\title{
Improving Education, Training and Employment Outcomes for Youth and Young Adults with Serious Mental Health Conditions
}

\author{
2018 State-of-the-Science \\ Conference Proceedings \\ Executive Summary
}


The Learning \& Working During the Transition to Adulthood Rehabilitation Research \& Training Center is a part of the Transitions to Adulthood Center for Research (Transitions ACR). Learn more about the Learning \& Working Center and the Transitions ACR by visiting our website at www.umassmed.edu/TransitionsACR.

The contents of these proceedings were developed under a grant with funding from the National Institute on Disability, Independent Living, and Rehabilitation Research, and from the Center for Mental Health Services, Substance Abuse and Mental Health Services Administration (SAMHSA, United States Department of Health and Human Services (NIDILRR grant number 90RT5031). NIDILRR is a Center within the Administration for Community Living (ACL), Department of Health and Human Services (HHS). The contents of this annotated bibliography do not necessarily represent the policy of NIDILRR, ACL, HHS, or of SAMHSAand you should not assume endorsement by the Federal Government.

Recommended citation: Maryann Davis. (2019). State-of-the-Science Conference Proceedings. Worcester, MA: University of Massachusetts Medical School, Implementation Science and Practice Advances Research Center, Transitions to Adulthood Center for Research.

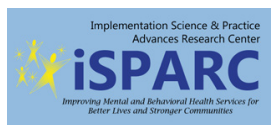




\section{Executive Summary}

The Learning and Working During the Transition to Adulthood Rehabilitation Research \& Training Center (Learning \& Working Center; LWC), University of Massachusetts Medical School, conducted a state-of-the-science conference, "Improving Education, Training and Employment Outcomes for Youth and Young Adults with Serious Mental Health Conditions." The State-of-the-Science Conference was held during and at the end of the 31st Annual Research and Policy Conference on Child, Adolescent, and Young Adult Behavioral Health (a.k.a. The Tampa Conference) in Tampa, Florida sponsored by the University of South Florida between March 4-7, 2018. The LWC held a post-Tampa Conference "think tank" session with 28 participants to summarize the current knowledge base on the education, training, and work lives of youth and young adults with serious mental health conditions (SMHCs) and to identify future research needed to move the field forward.

\section{Conference Goals}

There were two main goals for the state-of-the-science conference. The first was to describe the current state-of-the-science that informs practice and policy supports for strong educational and employment outcomes in youth and young adults (ages 14-30) with SMHCs. The second was to engage all attendees in prioritizing the knowledge that future research should address to most rapidly and robustly lead to improvements in these outcomes.

\section{Expert Listeners}

Thirteen "Listeners", who are experts from different roles in the field of young adult mental health, were invited to participate in the state-of-the-science conference. Listeners represented a wide range of perspectives and areas of expertise, including psychiatric rehabilitation in adults, lived experience, justice system involved youth and young adults, the foster care system, and policies (see the participant list in Section V). As a starting point for conference discussion, the Listeners were asked to attend specific research presentations related to the-state-of-the-science during the Tampa Conference (see the presentation list in section III).

To ensure that each Listener had a similar point of reference for the state-of-the-science in the field of education, training, and work lives for youth and young adults, they were provided with an annotated bibliography highlighting the current knowledge base about employment and education for young adults with SMHCs, including research from the LWC and beyond (see Section I). They were also provided executive summaries from the LWC's 2013 State-of-the-Science Conference.

While attending each specified research session during the Tampa Conference, Listeners were asked to think about two questions. They were instructed to keep in mind that all questions should be answered regarding research-based knowledge that improves education and career outcomes for youth and young adults with serious mental health conditions (SMHCs). These questions were:

1. What important contribution does this session make to the research-based knowledge about educational and career outcomes for youth and young adults with SMHCs?

2. What are important weaknesses in this work that would hinder the current state of knowledge? 


\section{"Think Tank" Process}

Listeners then attended the LWC's March 7 State-of-the-Science Conference Think Tank meeting. Twenty-eight individuals, including the 13 Listeners, participated in the Think Tank meeting. Participants included federal and state directors and administrators of disability service systems, especially in the areas of employment and education, as well as those with experience and expertise as family and young adult representatives and researchers.

The Think Tank took on the form of small workgroups to which participants were assigned. Each workgroup discussed the three questions identified below, shared their thoughts about the nature of the current field of research and priorities for future research, came up with two or three key takeaways as a group, and had time for reporting out and for a larger workgroup discussion.

\section{Workgroup Discussion Questions:}

1. How would you describe the current state-of-the-science from what you have heard or read so far?

2. From your area of expertise, what is missing in the knowledge of the current-state-of-thescience? Is there research available in your field that should be brought to bear that is not being considered?

3. What research is of the highest priority to be conducted in the near future that will most rapidly and robustly lead to improvements in these outcomes?

\section{Think Tank Results}

Goal 1: Describe the current state-of-the-science that informs practice and policy supports for strong educational and employment outcomes in youth and young adults (ages 14-30) with serious mental health conditions (SMHCs).

There is:

- An emphasis on peer coaching and participatory action research.

- Strong qualitative work in collecting the education and employment histories of youth and young adults with SMHCs.

- Strong focus on psychiatric rehabilitation principles.

- Explorative work in the development of promising new intervention models.

Goal 2: Have a group discussion to prioritize what future research should address to most rapidly and robustly lead to improvements in education and employment outcomes for this population.

- Move promising models from exploratory trials to efficacy studies and beyond.

- Expand educational focus to include high school, vocational training programs, and 2-year colleges. 
- Increase efforts to fight discrimination and the stigma associated with having a mental health condition by focusing on public education, careful use of language and promoting youth and young adult self-advocacy and empowerment.

- Increase research efforts for marginalized, low-income, minority, and justice-involved populations.

- Develop a research policy agenda and adopt a top-down approach to pursuing policy change and best practices.

- Build on current dissemination strategies and create strategic plans for sharing findings and materials.

The state-of-the-science conference ended with a wrap-up and conclusions. The proceedings herein include all conference papers and responses as well as final considerations for the future research directions in education, employment and policy and practice. 


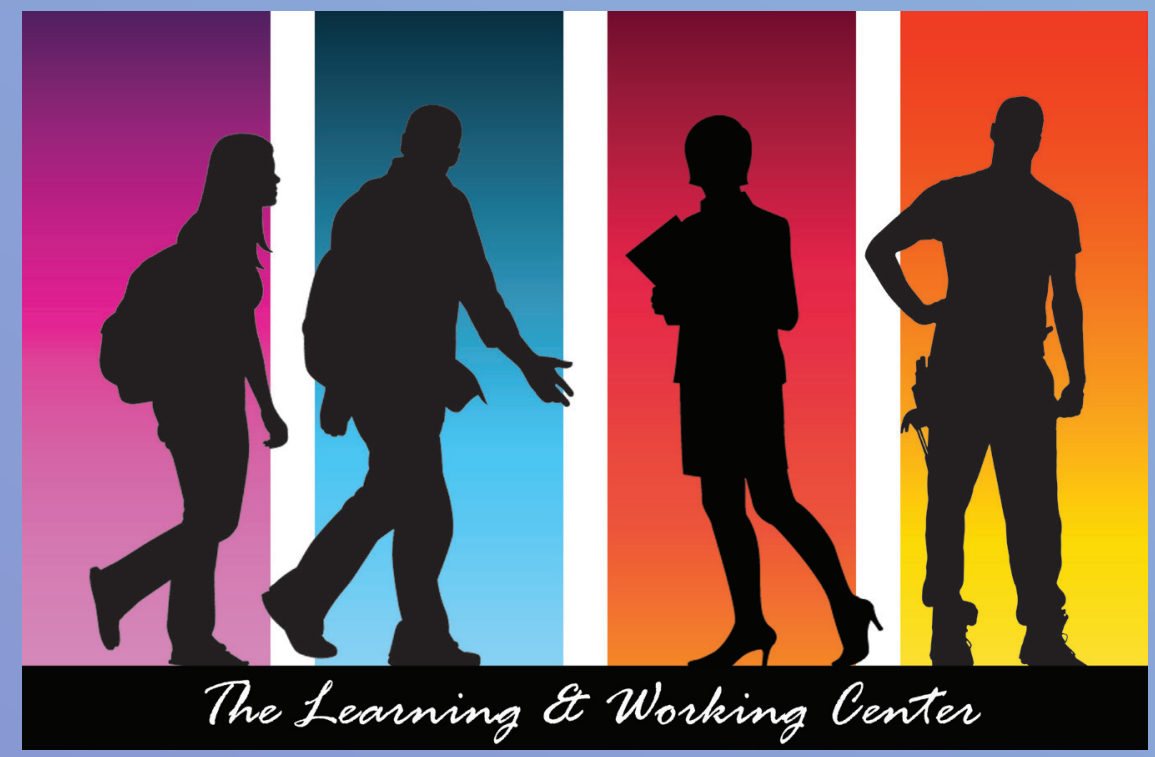

Download these proceedings and other products through our website at www.umassmed.edu/TransitionsACR 